\title{
PRIORITAS STRATEGI KELEMBAGAAN PENGELOLAAN SUMBER DAYA IKAN LESTARI BERBASIS OTONOMI DAERAH DI KAWASAN SELAT BALI
}

\section{Prioritized Strategies for Institutions in Sustainable Capture Fisheries Resources Management Within Autonomy Governance Context in Bali Strait}

Oleh:

Syafril Fauzi1 ${ }^{*}$, Budhi H. Iskandar², Bambang Murdiyanto², Eko S. Wiyono²

\author{
${ }^{1}$ Kementerian Kelautan dan Perikanan Republik Indonesia \\ 2Departemen Pemanfaatan Sumber Daya Perikanan, FPIK, IPB \\ *Korespondensi: syafril_fauzi@yahoo.com
}

Diterima: 29 September 2010; Disetujui: 2 Maret 2011

\begin{abstract}
This paper describes some prioritised strategies and its concept of implementation for institution related to capture fisheries resources in Bali Strait within local governance context in order to implement sustainable fiheries concept. Analysis Hierachy Process (AHP) was applied to construct the sequence of priorities. The results show that prioritised strategy, in sequence, were management development is carried out by specific institution that formed by local goverment (RK $=0,284$ ), intensively coordination in local government to control fishing gear allocation and conflict $(R K=0,243)$, development of all management effort by each local government $(R K=0,216)$, development of intensively coordination of local government in each managemnent activities ( $R K=$ 0,148 ) and developmentof intensively of local government to control fishing gear allocation and fishing ground $(R K=0,109)$. Implementation concept of prioritised strategy (management development is carried out by specific institution that formed by local government) was the specific institution should play roles as an excecutor of fisheries resources conservation program, as a manager in fish resources utilization appropriate to SKB (catch quota, number of fishing gear, potential fishing ground), as a controller in selling price and fishing gears operation periodically, as an information centre of human resources in fisheries and its development and as a facilitator in development of local income generating contributed from fisheries sector.
\end{abstract}

Key words: coordination, institution, strategy and fish resources

\begin{abstract}
ABSTRAK
Potensi perikanan Selat Bali terutama dari jenis ikan lemuru yang sangat besar, namun kegiatan pengelolaannya belum berjalan efektif dan efisien. Tulisan ini menjabarkan prioritas strategi kelembagaan yang tepat dan konsep implementasi dari strategi tersebut untuk pengelolaan sumber daya ikan (SDI) lestari berbasis otonomi daerah. Metode AHP digunakan dalam penentuan prioritas tersebut. Hasil analisis menunjukkan bahwa prioritas strategi pengembangan kelembagaan pengelolaan SDI lestari berbasis otonomi daerah di Selat Bali
\end{abstract}


adalah pengembangan pengelolaan dilakukan oleh lembaga khusus yang dibentuk bersama oleh PEMDA terkait $(R K=0,284)$, pengembangan koordinasi intensif PEMDA dalam kontrol alokasi alat tangkap dan konflik (RK $=0,243$ ), pengembangan semua bentuk kegiatan pengelolaan oleh PEMDA masing-masing $(R K=0,216)$, pengembangan koordinasi intensif PEMDA dalam setiap aktivitas pengelolaan ( $\mathrm{RK}=0,148)$ dan pengembangan koordinasi intensif PEMDA dalam kontrol alokasi alat tangkap dan lokasi tangkap $(\mathrm{RK}=0,109)$. Konsep implementasi dari strategi prioritas (pengelolaan oleh lembaga khusus bentukan bersama PEMDA terkait) adalah lembaga tersebut menjadi pelaksana program konservasi SDI, mengatur pemanfaatan SDI sesuai SKB (kuota tangkap, jumlah alat tangkap, lokasi tangkap potensial), mengontrol harga jual dan operasi alat tangkap secara periodik, pusat informasi tenaga kerja perikanan dan pembinaannya, dan fasilitator dalam perencanaan PAD dari sektor perikanan.

Kata kunci: koordinasi, lembaga, strategi, sumber daya ikan

\section{PENDAHULUAN}

Kegiatan perikanan kawasan Selat Bali merupakan perikanan andalan bagi Kabupaten Banyuwangi, Kabupaten Jembrana, dan Kabupaten Buleleng. Hal ini karena potensi perikanan Selat Bali terutama dari jenis ikan lemuru yang sangat besar. Menurut DKP (2008) dan Tungki (2005), produksi ikan lemuru di Selat Bali terbagi dalam tiga daerah yaitu kabupaten Buleleng 1.208,17 ton per tahun atau $4 \%$ dari total produksi ikan lemuru di Selat Bali, Kabupaten Jembrana $13.574,91$ ton per tahun atau $49 \%$ dari total produksi, dan Muncar 13.099,65 ton per tahun atau $47 \%$ dari total produksi. Untuk Kabupaten Banyuwangi, hampir $80 \%$ kegiatan ekonominya merupakan kegiatan perikanan Selat Bali dengan basis di Muncar (Dinas Kelautan dan Perikanan Kabupaten Banyuwangi 2009).

Namun demikian, kegiatan pengelolaan perikanan yang terjadi belum berjalan efektif dan efisien. Hal ini antara lain karena tidak ada koordinasi yang baik diantara lembaga perikanan yang ada, dimana cukup banyak fungsi pengelolaan yang tumpang-tindih bahkan saling menghambat (Wudianto 2001). Di samping itu, stakeholders atau pelaku kelembagaan dari kabupaten/provinsi otonomi terkait mempunyai kepentingan masing-masing dalam pengelolaan perikanan.

Berkaitan dengan kondisi kelembagaan tersebut, dari hasil kajian terdahulu telah dihasilkan 5 (lima) strategi kelembagaan pengelolaan sumber daya ikan lestari dengan berbasis pada otonomi daerah. Namun demikian dalam implementasinya diperlukan prioritas agar pengeolaan perikanan dari aspek kelembagaan dapat berjalan efektif dan efisien. Kelima strategi itu adalah, (1) Pengembangan koordinasi intensif PEMDA dalam aktivitas pengelolaan; (2) Pengembangan koordinasi intensif PEMDA dalam kontrol alokasi alat tangkap dan Ikasi tangkap; (3) Pengembangan koordinasi intensif PEMDA dalam kontrol alokasi alat tangkap dan konflik; (4) Pengembangan pengelolaan dilakukan oleh lembaga khusus yan dibentuk bersama oleh PEMDA terkait; dan (5) Pengembangan semua bentuk kegiatan pengelolaan oleh PEMDA masing-masing.

Tujuan dari kajian ini adalah untuk menentukan prioritas strategi kelembagaan pengelolaan sumber daya ikan lestari berbasis otonomi daerah dan menyusun konsep implementasi dari strategi kelembagaan pengelolaan terpilih.

\section{METODE PENELITIAN}

\section{Waktu dan Lokasi Penelitian}

Penelitian ini dilaksanakan selama 9 (sembilan) bulan dimulai dari bulan Desember 2009 sampai dengan Agustus 2010. Lokasi penelitian adalah kawasan Selat Bali di Kabupaten Banyuwangi, Kabupaten Jembrana, dan Kabupaten Buleleng.

\section{Jenis Data yang Dikumpukan}

Data yang dikumpulkan dalam penelitian ini terdiri dari data primer dan data sekunder. Data primer mencakup data SDI, kondisi perairan, pendapatan, kesempatan kerja, alat tangkap, dan aspek sosial ekonomi lainnya. Data tersebut diperoleh dari perwakilan stakeholders di lokasi dari 20-25 responden sesuai persyaratan pogram AHP (Analitical Hierachy Process) yang digunakan (Expert Choice 9.5). Data sekunder mencakup data PAD, data terkait otonomi daerah dan PERDA terkait di kawasan Selat Bali. 


\section{Metode Pengumpulan Data}

\section{Metode pengumpulan data primer}

Pengumpulan data primer dilakukan melalui wawancara langsung dengan responden perwakilan stakeholders. Pengumpulan data ini dilakukan melalui tiga tahap, yaitu pemilihan kelompok sampling/stakeholders, identifikasi responden, dan pengumpulan data responden (Bungin 2004). Pengumpulan data ini dilakukan secara purposive kepada perwakilan stakeholders (hasil identifikasi) yang mempunyai pengalaman dan pengetahuan cukup tentang pengelolaan perikanan Selat Bali. Jumlah responden untuk kepentingan analisis AHP sebanyak 20 responden dari kelompok stakeholders terpilih. Kelompok tersebut terdiri dari nelayan, pengusaha perikanan, dinas kelautan dan perikanan, UPT perikanan, pengolah/pedagang ikan, dan masyarakat luas.

\section{Metode pengumpulan data sekunder}

Data sekunder dikumpulkan dengan cara telaah pustaka/studi literatur terkait dengan bahasan dalam tulisan ini, konsultasi pakar, dan kombinasi keduanya. Data sekunder ini dikumpulkandari berbagai sumber seperti kantor dinas perikanan, statistik, PEMDA setempat dan berbagai instansi lain yang terkait.

\section{Metode Analisis}

Analisis prioritas strategi kelembgaan ini dilakukan menggunakan metode AHP. Di dalam konsep AHP berbagai komponen yang berinteraksi dengan kegiatan perikanan dan otonomi daerah tersebut dikelompokkan ke dalam beberapa level/hierarki, misalnya level goal (tujuan), level kriteria, level pembatas (limit factor), dan level opsi strategi kelembagaan (Saaty 1991 dan Maarif 2004).

Adapun tahapan analisis terkait pengembangan strategi kelembagaan pengelolaan perikanan berbasis otonomi daerah adalah:

\section{1) Penetapan komponen}

Pada tahapan ini, semua komponen yang berkaitan dengan kelembagaan perikanan dan otonomi daerah ditetapkan dan didefinisikan;

\section{2) Penyusunan struktur hierarki}

Pada tahapan ini, semua interaksi komponen yang telah didefinisikan dalam bentuk struktur hierarki AHP yang dimulai tujuan umum (level 1), sub tujuan/kriteria (level 2), pembatas/limit factor (level 3) dan strategi interaksi kelembagaan pengelolaan perikanan lestari berbasis otonomi daerah (level 4);

\section{3) Penetapan skala banding dan pembo- botan}

Penetapan skala banding ini dan sistem pembobotannya mengacu kepada skala banding berpasangan menurut Saaty (1991). Pembobotan diberikan berdasarkan taraf relatif pentingnya suatu komponen dibandingkan dengan komponen lainnya di level yang sama;

\section{4) Formulasi data dan simulasi}

Formulasi data merupakan kegiatan menginput data hasil analisis skala banding perpasangan ke dalam struktur hierarki. Pembuatan hierarki dan input data ini dilakukan menggunakan Program Expert Choice 9.5, sedangkan data yang diinput disiapkan menggunakan program Microsoft Excel. Simulasi merupakan kegiatan menganalisis dan membandingkan data semua komponen yang ada;

\section{5) Pengujian hasil}

Tahapan ini bertujuan untuk menguji konsistensi dan sentivitas dari hasil simulasi yang telah dilakukan. Hasil simulasi diharapkan mempunyai rasio inconsistency < 0,1dan untuk uji sensitivitas diharapkan hasil simulasi yang tidak terlalu sensitif; dan

\section{6) Interpretasi hasil}

Tahapan interpretasi ini merupakan tahapan penggunaan hasil analisis AHP dalam menjelaskan dan memberikan rekomendasi prioritas strategi interaksi kelembagaan pengelolaan perikanan lestari berbasis otonomi daerah, serta kestabilan/ sensitifitasnya terhadap berbagai perubahan yang terjadi secara nyata di kawasan Selat Bali.

\section{Komponen Penyusun Hierarki Terpilih}

Pengembangan strategi kelembagaan sumber daya ikan (SDI) lestari berbasis otonomi daerah di kawasan Selat Bali ini sangat diten-tukan oleh kepentingan kriteria yang ada, kon-disi pengelolaan yang ada saat ini, dan alternatif strategi kelembagaan pengelolaan sumber daya ikan yang ditawarkan. Hasil kajian tentang kesejahteraan, dinamika produksi, dan kelayakan usaha dalam 
penelitian ini menun-jukkan ada lima kriteria penting yang harus dicapai dalam pengembangan strategi kelem-bagaan pengelolaan SDI lestari berbasis oto-nomi daerah di kawasan Selat Bali, yaitu:

a. Potensi SDI lestari;

b. Pendapatan rumah tangga nelayan (RTN) meningkat;

c. Kesempatan kerja meningkat;

d. Selektifitas alat tangkap baik; dan

e. PAD meningkat.

Di dalam struktur hierarki AHP, kelima kriteria ini berada di level 2 setelah goal (strategi kelembagaan pengelolaan SDI) di level 1.

Strategi kelembagaan pengelolaan SDI lestari berbasis otonomi daerah di Selat Bali ini juga dipengaruhi berbagai kendala atau faktor pembatas dalam pengelolaan perikanan di kawasan Selat Bali. Adapun faktor pembatas penting tersebut diantaranya (DKP 2008 dan Dinas Kelautan dan Perikanan Kabupaten Buleleng 2009) adalah :

a. Kondisi perairan, dimana akvitas penyeberangan yang padat dan kegiatan penangkapan ikan yang intensif, sehingga berpeluang mencemari perairan;

b. Kewenangan otonomi, yang disatu sisi memberi peran luas bagi PEMDA dalam pengelolaan dan di sisi lain dapat menghambat kegiatan pengelolaan karena setiap PEMDA membuat kepentingan masing-masing dalam pengelolaan;

c. Kualitas SDM perikanan, yang juga masih terbatas baik dalam kuantitas maupun kualitas; dan

d. Lingkungan sosial, juga membatasi karena adanya tata nilai yang berlaku dan diikuti secara turun temurun.

Faktor pembatas tersebut akan menentukan dan mempengaruhi pemenuhan kriteria pengembangan kelembagaan pengelolaan sumber daya ikan yang perlu dicapai, struktur hierarki AHP berada di level 3.

Penetapan alternatif strategi ditentukan dari hasil kajian kelembagaan yang dihubungkan dengan kondisi ril yang ada di lokasi. Adapun alternatif strategi tersebut adalah:

a. Pengembangan koordinasi intensif PEMDA dalam setiap aktivitas pengelolaan; b. Pengembangan koordinasi intensif PEMDA dalam kontrol alokasi alat tangkap dan lokasi tangkap;

c. Pengembangan koordinasi intensif PEMDA dalam kontrol alokasi alat tangkap dan konflik;

d. Pengembangan pengelolaan dilakukan oleh lembaga khusus yang dibentuk bersama oleh PEMDA terkait; dan

e. Pengembangan semua bentuk kegiatan pengelolaan oleh masing-masing PEMDA.

\section{HASIL DAN PEMBAHASAN}

\section{Rancangan Struktur Hierarki}

Rancangan hierarki ini merupakan hasil pengembangan hubungan atau interaksi terpadu semua komponen yang terkait dengan pengelolaan perikanan di kawasan Selat Bali. $\mathrm{Hal}$ ini penting supaya strategi kelembagaan pengelolaan sumber daya ikan yang dipilih benar-benar merupakan strategi terbaik yang telah mempertimbangkan berbagai faktor pembatas/komponen yang terkait baik secara horizontal maupun vertikal. Untuk mendapatkan hasil yang menyeluruh dan akurat, maka dalam AHP ini dikembangkan analisis bertingkat, dimana setiap komponen diperbandingkan satu sama lainnya di tingkat yang sama dan hasilnya dikombinasikan dengan hasil pada hierarki/ tingkatan atas maupun bawahnya.

Berdasarkan berdasarkan uraian di atas, maka dapat dirancang struktur hierarki strategi kelembagaan pengelolaan SDI berbasis otonomi daerah di Selat Bali seperti ditunjukkan pada Gambar 1. Pada gambar tersebut terlihat bahwa dalam penentuan alternatif strategi kelembagaan pengelolaan SDI berbasis otonomi daerah di Selat Bali, dilakukan melalui tiga tahapan analisis hierarki, yaitu a) analisis kepentingan lima kriteria pengembangan kelembagaan pengelolaan sumber daya ikan yang perlu dicapai bila suatu strategi dipilih nantinya, b) analisis kepentingan empat faktor pembatas dalam pengelolaan perikanan di kawasan Selat Bali, dan c) analisis kepentingan alternatif stra-tegi kelembagaan pengelolaan SDI berbasis otonomi daerah di Selat Bali. Untuk menga-komodir harapan semua kepentingan yang ada, maka data yang digunakan dalam analisis hierarki AHP merupakan pendapat/tanggapan dari perwakilan semua stakeholders dan kom-ponen yang berinteraksi/terkait dengan penge-lolaan sumber daya perikanan di kawasan Selat Bali. 


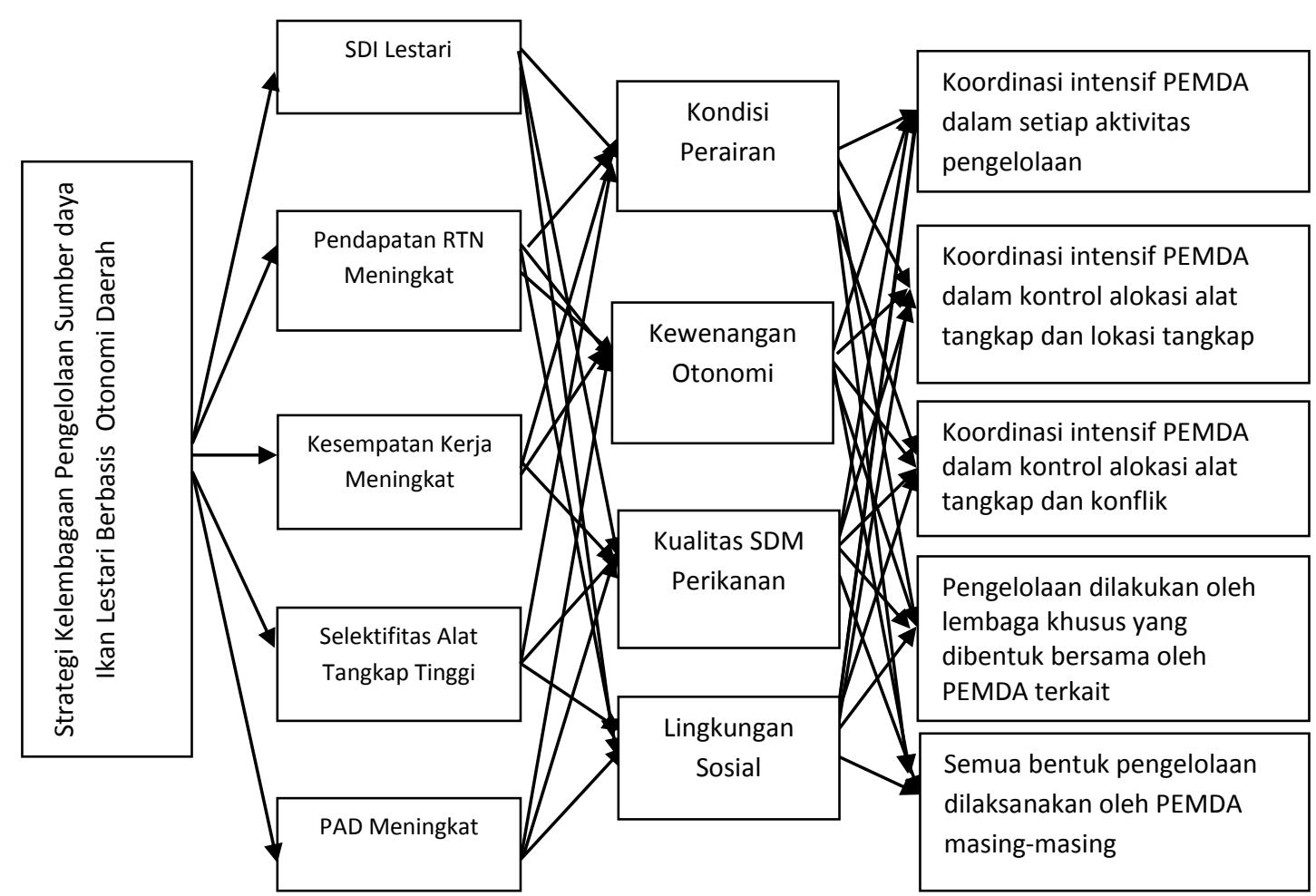

Gambar 1 Struktur hierarki strategi kelembagaan pengelolaan SDI berbasis otonomi daerah di Selat Bali.

\section{Kepentingan Alternatif Strategi Kelemba- gaan}

Sebelum sampai kepada analisis kepentingan alternatif startegi kelembagaan, dilakukan analisis terlebih dahulu terhadap kriteria dan faktor pembatas startegi yang dibangun. Analisis dilakukan terhadap kepentingan pengembangan kelembagaan berdasarkan 5 (lima) kriteria yang dibangun dan kepentingan faktor pembatas pengelolaan, yang dalam bahasan ini terdapat 4 (empat) faktor pembatas sebagaimana telah disebutkan di atas. Interakasi antara keduanya sangat menentukan prioritas strategi yang dihasilkan dari analisis ini.

Hasil analisis terhadap kelima kriteria tersebut menunjukkan bahwa kriteria potensi SDI lestari merupakan kriteria yang paling berkepentingan dengan nilai rasio kepentingan sebesar 0,309 diikuti berturut turut oleh kriteria kesempatan kerja $(0,262)$, selektifitas alat tangkap tinggi $(0,186)$, pendapatan rumah tangga nelayan meningkat $(0,162)$ dan PAD meningkat $(0,081)$. Kriteria SDI lestari berada pada nilai rasio kepentingan terbesar, hal ini didukung oleh pendapat Bjorndal dan Zug (1995) dimana kelestarian sumber daya hayati menjadi faktor penentu utama kegiatan pemanfaatan di perairan laut. Oleh karena itu kegiatan pemanfaatan yang bertanggungjawab dan konservasi habitat selalu harus dikedepankan dalam semua kegiatan pengelolaan.

Hasil analisis terhadap keempat faktor pembatas menunjukkan bahwa kondisi perairan merupakan faktor pembatas yang paling penting untuk diperhatikan dalam memenuhi kriteria potensi SDI lestari, dengan nilai rasio kepentingan 0,340 . Selanjutnya diikuti berturutturut oleh faktor pembatas lingkungan sosial $(0,309)$, kualitas sumber daya perikanan $(0,230)$ dan kewenangan otonomi $(0,121)$. Hasil ini cukup wajar karena kondisi perairan mempu-nyai hubungan dan pengaruh langsung dengan perkembangan sumber daya ikan, sehingga bila kondisi peraran baik maka sumber daya ikan bisa tumbuh dan berkembang dengan baik.

Selanjutnya dari hasil analisis tersebut, dilakukan analisis prioritas terhadap strategi yang dihasilkan. Hasil analisis ini merupakan tujuan akhir dari analisis AHP terkait prioritas strategi kelembagaan pengelolaan sumber daya ikan (SDI) berbasis otonomi daerah di kawasan Selat Bali. Hasil analisis ini telah mengako-modir kepentingan dari kriteria 
pengembangan kelembagaan pengelolaan dan faktor pembatas pengelolaan yang telah dibahas pada bagian sebelumnya. Hasil analisis rasio kepentingan setiap alternatif strategi kelembagaan pengelo-laan sumber daya ikan berbasis otonomi daerah di Selat Bali tersebut setelah diolah menggu-nakan sofware TeamEC ditunjukkan pada Gambar 2.

Berdasarkan Gambar 2, alternatif pengembangan pengelolaan dilakukan oleh lembaga khusus yang dibentuk bersama oleh PEMDA terkait (PPLKB) mempunyai rasio kepentingan paling tinggi dibandingkan lima alternatif strategi kelembagaan pengelolaan lainnya, yaitu mencapai 0,284 pada inconsistency terpercaya 0,05. Batas inconsistency yang diperbolehkan secara statistik adalah tidak lebih dari 0,1 . Dengan demikian, maka alternatif PPLKB ini menjadi strategi prioritas pertama untuk pengembangan kelembagaan pengelolaan sumber daya ikan lestari berbasis otonomi daerah di kawasan Selat Bali. Strategi PPLKB memberi fokus pada pengelolaan sumber daya ikan yang lebih fokus dan terintegrasi sehingga sumber daya ikan tetap lestari, dan kelestarian ini haruslah menjadi ujung tombok semua kegiatan pengelolaan sumber daya perikanan (Musick et al. 2008).

\section{Sensitivitas Strategi Kelembagaan Penge- Iolaan Terpilih}

Bagian sebelumnya menunjukkan bahwa pengembangan pengelolaan dilakukan oleh lembaga khusus yang dibentuk bersama oleh PEMDA terkait (PPLKB) merupakan strategi terpilih (prioritas I) untuk terkait kelembagaan pengelolaan sumber daya ikan berbasis otonomi daerah di kawasan Selat Bali. Untuk memu-dahkan implementasinya, strategi terpilih perlu diuji sensitivitasnya.

Informasi tentang sensitifitas ini tidak hanya penting untuk mengetahui keunggulan strategi pengembangan pengelolaan dilakukan oleh lembaga khusus yang dibentuk bersama oleh PEMDA terkait (PPLKB) dalam pengembangan kelembagaan pengelolaan sumber daya ikan, tetapi juga penting untuk membuat langkah antisipasi pengelolaan akibat berbagai perubahan yang mungkin terjadi di lokasi yang ada di lokasi. Informasi tersebut juga menjadi panduan untuk implementasi berbagai program dan kebijakan terkait pengelolaan sumber daya termasuk dengan basis otonomi daerah di kawasan Selat Bali atau lokasi lainnya. Informasi aplikatif terkait suatu kebijakan dapat berfungsi sebagai rambu-rambu dalam implementasi stau kebijakan pengelolaan (Sheppard et al. 1995).

Dalam kehidupan nyata, berbagai perubahan dalam pengelolaan sumber daya ikan umumnya terjadi akibat adanya intervensi dari pihak-pihak yang berkepentingan di lokasi, seperti nelayan, pengusaha perikanan, pemerintah daerah, pedagang ikan, pengusaha industri, perilaku pasar dan lainnya. Strategi pengembangan pengelolaan dilakukan oleh lembaga khusus yang dibentuk bersama oleh PEMDA terkait (PPLKB) harus dapat mensiasati berbagai perubahan tersebut sehingga statusnya sebagai strategi kelembagaan terpilih tetap dapat diandalkan. Perubahan tersebut dapat berupa perubahan kepentingan kriteria pengembangan kelembagaan dan pengelolaan perikanan di kawasan Selat Bali akibat interaksi dan intervensi dari stakholders terkait. Kriteria yang dimaksud adalah potensi sumber daya ikan (SDI) tetap lestari di perairan Selat Bali, pendapatan rumah tangga nelayan (RTN) meningkat, kesempatan kerja meningkat, selektifitas alat tangkap baik, dan pendapatan asli daerah meningkat. Sedangkan stakeholders yang bisa menjadi penyebab perubahan karena interaksi/intervensinya adalah nelayan, pengusaha perikanan, pemerintah daerah, nelayan, pedagang ikan, industri perikanan, pengelola prasarana perikanan di kawasan, perilaku pasar, dan lainnya (Setiawan et al. 2007). Tabel 1 memberikan arahan implementatif bagi strategi pengembangan pengelolaan dilakukan oleh lembaga khusus yang dibentuk bersama oleh PEMDA terkait (PPLKB) untuk mensiasati berbagai perubahan tersebut.

\section{Konsep Strategi Kelembagaan Pengelo- laan Terpilih}

\section{Konsep implementasi untuk perubahan kriteria yang tidak sensitif}

Berdasarkan Tabel 1, pengembangan pengelolaan dilakukan oleh lembaga khusus yang dibentuk bersama oleh PEMDA terkait (PPLKB) tidak mempunyai range sensitif terhadap perubahan yang terjadi pada kriteria potensi sumber daya ikan (SDI) tetap lestari di perairan Selat Bali, pendapatan rumah tangga nelayan (RTN) meningkat, kesempatan kerja meningkat, dan selektifitas alat tangkap baik. Terkait dengan ini, jika strategi pengembangan pengelolaan dilakukan oleh lembaga khusus yang dibentuk bersama oleh PEMDA terkait (PPLKB) diimplementasikan, maka tidak akan terpengaruh oleh perubahan apapun potensi SDI, pendapatan RTN, kesempatan kerja, dan selektifitas alat tangkap. 
Synthesis of Leaf Nodes with respect to GOAL

kleal ricote

OVERALL INCONSETENCY INDEX - 0.05

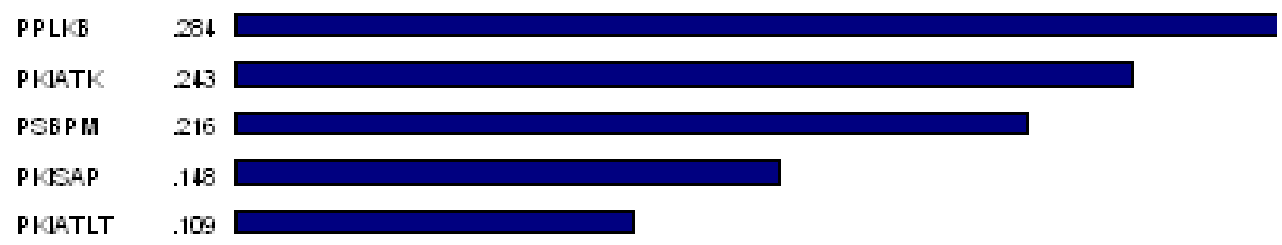

\begin{tabular}{|l|l|}
\hline Abbreviation & \multicolumn{1}{|c|}{ Definition } \\
\hline PPLKB & $\begin{array}{l}\text { Pengembangan Pengelolaan Oleh Lembaga Khusus Bentukan } \\
\text { Bersama }\end{array}$ \\
\hline PKIATK & $\begin{array}{l}\text { Pengembangan Koord. Intensif PEMDA Kontrol Alat Tangkap \& } \\
\text { Konflik }\end{array}$ \\
\hline PSBPM & $\begin{array}{l}\text { Pengembangan Semua Bentuk Pengelolaan Oleh PEMDA } \\
\text { Masing-Masing }\end{array}$ \\
\hline PKISAP & Pengembangan Koord. Intensif PEMDA Setiap Akt. Pengelolaan \\
\hline PKIATLT & $\begin{array}{l}\text { Pengembangan Koord. Intensif PEMDA Kontrol Alat Tangkap \& } \\
\text { Lokasi }\end{array}$ \\
\hline
\end{tabular}

Gambar 2 Hasil analisis kepentingan alternatif strategi kelembagan pengelolaan untuk keseluruhan pertimbangan.

Tabel 1 Arahan implementatif bagi alternatif strategi PPLKB untuk mensiasati berbagai perubahan kepentingan kriteria pengembangan di kawasan Selat Bali.

\begin{tabular}{|c|c|c|c|c|}
\hline \multirow{2}{*}{ No. } & \multirow{2}{*}{ Kriteria Pengembangan } & \multirow{2}{*}{$\begin{array}{c}\text { Rasio } \\
\text { Kepentingan } \\
\text { Awal (RK Awal) }\end{array}$} & \multicolumn{2}{|c|}{$\begin{array}{c}\text { Arahan Implementasi } \\
\text { Alternatif Strategi PPLKB }\end{array}$} \\
\hline & & & $\begin{array}{l}\text { Range RK } \\
\text { Stabil }\end{array}$ & $\begin{array}{c}\text { Range RK } \\
\text { Sensitif }\end{array}$ \\
\hline 1 & Potensi SDI Lestari & 0,309 & $0-1$ & Tidak Ada \\
\hline 2 & Pendapatan RTN Meningkat & 0,162 & $0-1$ & Tidak Ada \\
\hline 3 & $\begin{array}{l}\text { Kesempatan Kerja } \\
\text { Meningkat }\end{array}$ & 0,262 & $0-1$ & Tidak Ada \\
\hline 4 & $\begin{array}{l}\text { Selektifitas Alat Tangkap } \\
\text { Meningkat }\end{array}$ & 0,186 & $0-1$ & Tidak Ada \\
\hline 5 & PAD Meningkat & 0,081 & $0-<0,672$ & $0,672-1$ \\
\hline
\end{tabular}

Sumber : Hasil analisis $A H P(2010)$

Mengacu kepada hal ini, maka ada beberapa konsep yang bisa diacu dalam implementasi strategi PPLKB ini, yaitu :

a. Lembaga khusus yang dibentuk bersama oleh PEMDA terkait dapat diandalkan sebagai pelaksana berbagai kegiatan konservasi sumber daya ikan di kawasan Selat Bali. Lembaga tersebut dapat melakukan penelitian lintas perairan kabupaten untuk menetapkan lokasi yang tepat untuk melakukan konservasi (pelepasan bibit ikan, pelestarian terumbu karang sebagai habitat ikan, dan lainnya). Pembiayaan kegia- tan konservasi berasal dari sharing PEMDA terkait.

b. Lembaga khusus yang dibentuk bersama oleh PEMDA terkait dapat menetapkan aturan pemanfaatan sumber daya ikan bagi semua jenis usaha perikanan termasuk usaha pengolahan dan pemasaran hasil tangkapan. Terkait dengan ini, lembaga tersebut dapat menetapkan jenis alat tang-kap yang beroperasi, memberi rekomen-dasi lokasi penangkapan, mengatur jumlah alat tangkap, dan mengontrol kuota alat tangkap setiap daerah berdasarkan keten- 
tuan yang ditetapkan dalam SKB. Pengaturan oleh lembaga ini tetap lebih efektif baik pada kondisi musim puncak, sedang, maupun pacekelik (karena tidak ada RK sensitif terkait SDI). Untuk usaha pengolahan dan pemasaran, lembaga khusus ini dapat mengatur kuota setiap industri pengolahan di kawasan Selat Bali dan kuota hasil tangkapan yang dilepas ke pasar, sehingga tidak ada monopoli dan setiap industri dapat berkembang lebih baik. Secara periodek, semua kegiatan pengaturan pemanfaatan tersebut dikoordinasi kepada PEMDA terkait.

c. Lembaga khusus yang dibentuk bersama oleh PEMDA terkait dapat mengontrol harga jual yang berlaku. Harga jual ikan hasil tangkapan diatur sedemikianrupa, sehingga baik nelayan, pedagang ikan maupun industri pengolahan mendapatkan keuntungan yang wajar dan layak. Pengontrolan harga ini dapat dilakukan terusmenerus oleh lembaga tersebut, baik pada musim puncak, sedang, maupun pacekelik, baik ikan hasil tangkapan tersebut ditujukan untuk pasar lokal, nasional maupun ekspor. Hal ini penting untuk menghindari monopoli harga termasuk oleh pihak-pihak yang mengaku punya jaringan di pasar lebih luas (nasional maupun ekspor). Dengan demikian, pendapatan nelayan dan masyarakat sekitar tetap layak dan bahkan menjadi lebih baik.

d. Lembaga khusus yang dibentuk bersama oleh PEMDA terkait dapat berperan menjadi pusat informasi tenaga kerja di bidang perikanan. Untuk mendapatkan informasi lowongan kerja, lembaga ini dapat bekerjasama dengan kelompok nelayan, serikat pekerja pelabuhan dan industri pengolahan yang ada di kawasan Selat Bali. Bila peran ini dapat dilakukan, maka kesempatan kerja akan lebih mudah didapat, sedangkan pengusaha perikanan dan industri akan lebih mendapatkan tenaga kerja yang dibutuhkannya. Bersama dengan PEMDA, lembaga ini juga dapat membuat program pelatihan bagi calon tenaga kerja perikanan, sehingga kualitasnya lebih baik dan siap pakai.

e. Lembaga khusus yang dibentuk bersama oleh PEMDA terkait dapat secara periodik mengontrol alat tangkap yang digunakan nelayan. Hal ini penting supaya alat tangkap yang digunakan nelayan tetap sesuai dengan ketentuan dan mempunyai selektifitas yang tinggi. Pengontrolan alat tangkap ini dapat dilakukan baik pada musim puncak, sedang, maupun pacekelik dan tidak akan mengganggu aktivitas penangkapan yang dilakukan nelayan (tidak ada RK sensitif terkait selektifitas alat tangkap, Tabel 1).

\section{Konsep implementasi untuk perubahan kriteria yang sensitif}

Berdasarkan Tabel 1, pengembangan pengelolaan dilakukan oleh lembaga khusus yang dibentuk bersama oleh PEMDA terkait (PPLKB) mempunyai range sensitif terhadap perubahan yang terjadi pada kriteria pendapatan asli daerah meningkat (PAD), yaitu pada kisaran 0,672 - 1. Hal ini menunjukkan bahwa bila PEMDA terlalu berorientasi pada peningkatan pajak dalam semua kegiatan pengelolaan perikanan di kawasan Selat Bali (RK PAD ditingkatkan dari 0,081 menjadi 0,672 atau lebih), maka tugas pengelolaan yang dilakukan oleh lembaga khusus bentukan bersama PEMDA terkait menjadi tidak efektif.

Terkait dengan PAD ini, maka konsep yang bisa diacu dalam implementasi strategi PPLKB ini, yaitu:

a. Lembaga khusus yang dibentuk bersama oleh PEMDA terkait dapat menjadi fasilitator dalam perencanaan pendapatan asli daerah pada bidang perikanan di kawasan Selat Bali. Lembaga khusus bentukan bersama PEMDA dapat diisi oleh perwakilan stakholders terkait seperti perwakilan nelayan,koperasi, HNSI, pedagang ikan, dan lainnya. Lembaga ini nantinya akan mencatat dan mengelola data dan informasi terkait pemanfaatan sumber daya ikan, harga jual, kapasitas/kuota industri, penyerapan tenaga kerja pada kegiatan pengolahan karena diberi peran dalam pengaturan dan pengkoordinasiannya. Terkait hal ini, maka lembaga khusus ini dapat memberikan masukan tentang potensi PAD perikanan yang tepat dan wajar bagi PEMDA terkait (Putra 2000).

b. Dalam koordinasi perencanaan PAD dengan lembaga khusus bentukan bersama PEMDA ini, PEMDA terkait hendaknya menerapkan prinsip saling percaya dalam artian PEMDA menetapkan besaran PAD berdasarkan potensi yang mungkin di kawasan Selat Bali dan telah didata oleh lembaga tersebut.

c. PEMDA sebaiknya menghindari pemungutan retribusi berlapis dan tidak lazim dalam pengelolaan perikanan. Bila hal ini dipaksakan, maka akan timbul konflik 
dengan nelayan dan masyarakat sekitar, sehingga memacu mereka untuk melanggar kesepakatan pengelolaan seperti melakukan penangkapan ikan destruktif guna menutupi besarnya biaya, menjual hasil tangkapan secara illegal untuk mendapatkan keuntungan yang lebih besar, dan lainnya. Bila hal ini berlanjut, maka kegiatan pengelolaan sumber daya ikan lestari berbasis otonomi daerah tidak akan bertahan lama.

Terkait dengan hal tersebut, maka untuk masalah pencapaian PAD tinggi, PEMDA terkait hendaknya lebih berhat-hati dan mencegah pungutan-pungutan yang tidak lazim. Lembaga khusus yang dibentuk bersama, harus diminta masukannya dalam perencanaan PAD, dan data pengelolaan yang dimiliki oleh lembaga tersebut hendaknya menjadi acuan dalam setiap upaya memperbesar kontribusi PAD di bidang perikanan di kawasan Selat Bali. Mengacu kepada Tabel 1, PAD sebenarnya dapat juga ditingkatkan asal tidak terlalu siginfikan dan dilakukan secara bertahap sesuai perkembangan kegiatan pengelolaan perikanan di kawasan Selat Bali.

\section{KESIMPULAN DAN SARAN}

\section{Kesimpulan}

Berdasarkan urutan prioritasnya, strategi pengembangan kelembagaan pengelolaan SDI lestari berbasis otonomi daerah di Selat Bali adalah pengembangan pengelolaan dilakukan oleh lembaga khusus yang dibentuk bersama oleh PEMDA terkait ( $R K=0,284)$, pengembangan koordinasi intensif PEMDA dalam kontrol alokasi alat tangkap dan konflik (RK = 0,243 ), pengembangan semua bentuk kegiatan pengelolaan oleh PEMDA masing-masing (RK $=0,216)$, pengembangan koordinasi intensif PEMDA dalam setiap aktivitas pengelolaan (RK $=0,148$ ) dan pengembangan koordinasi intensif PEMDA dalam kontrol alokasi alat tangkap dan lokasi tangkap ( $R K=0,109$ ). Mengacu kepada data RK ini, maka pengembangan pengelolaan dilakukan oleh lembaga khusus yang dibentuk bersama oleh PEMDA menjadi strategi prioritas.

Dalam implementasi strategi prioritas, maka lembaga khusus bentukan bersama PEMDA terkait dapat berperan sebagai pelaksana program konservasi SDI, mengatur pemanfaatan SDI sesuai SKB (kuota tangkap, jumlah alat tangkap, lokasi tangkap potensial), mengontrol harga jual dan operasi alat tangkap secara periodik, pusat informasi tenaga kerja perikanan dan pembinaannya, dan fasilitator dalam perencanaan PAD dari sektor perikanan.

\section{Saran}

PEMDA terkait hendaknya membericarakan secara detail operasinal lembaga khusus bentukan bersama tersebut (strategi prioritas) terutama menyangkut jalur koordinasi, wewenang dan pertanggungungjawaban. Namun demikian, PEMDA terkait perlu memberi keleluasaan penuh kepada lembaga tersebut dalam pelaksanaan tugasnya.

\section{DAFTAR PUSTAKA}

Bungin B. 2004. Metode Penelitian Kuantitatif. Raja Grafindo Persada. Jakarta.

Bjorndal K.A., and G.R. Zug. 1995. Growth and Age of Sea Turtle, in Bjorndal, K.A., editor. Biology and Conservation of Sea Turtle. Smithsonian Institution Press, Washington, D.C.

Departemen Kelautan dan Perikanan [DKP]. 2008. Studi Pengembangan Kebijakan Perikanan Berbasis Kawasan. Program Kerjasama Ditjen KP3K-DKP. Jakarta.

Dinas Kelautan dan Perikanan Kabupaten Banyuwangi. 2010. Pengelolaan Potensi Perikanan Selat Bali, Tantangan dan Permasalahannya. Dinas Kelautan dan Perikanan Kabupaten Banyuwangi. Banyuwangi.

Dinas Kelautan dan Perikanan Kabupaten Buleleng. 2009. Prospek Pengelolaan Potensi Perikanan Wilayah Barat Kabupaten Buleleng. Laporan Kegiatan. Singaraja.

Maarif S. 2004. Analisis Hierarki Proses. Bahan Kuliah Program Studi PSL-SPS IPB. Bogor.

Musick J.A, S.A. Berkeley, G.M. Cailliet, M. Camhi, G. Huntsman, M. Nammack, and M.L. Warren. 2008. Protection of Marine Fish Stocks at Risk of Extinction. Fisheries of Jr. Maret 2008.

Putra S. 2000. Konflik Pengelolaan Sumber Daya Kelautan di Sulawesi Utara Dapat Mengancam Kelestarian Pemanfaatannya. Jurnal Depdagri Vol 12. Jakarta.

Saaty T.L. 1991. Pengambilan Keputusan bagi Para Pemimpin. PT. Pustaka Binaman Pressindi. Jakarta. 
Sheppard C.R.C., Matheson K., Bythell J. C., Edwards A. J., Murphy P., Blair-Myers C., and Blake B. 1995. Habitat mapping in the Caribbean for Management and conservation: use and assessment of aerial photography. AquaticCon servation: Marine and Freshwater Ecosystems. 5, 277-298.

Setiawan I., Monintja D.R., Nikijuluw V.P.H., dan Sondita M.F.A. 2007. Analisis Ketergantungan Daerah Perikanan sebagai Dasar Pelaksanaan Program Pemberdayaan Nelayan: Studi Kasus di Kabupaten Cirebon dan Indramayu. Buletin PSP Vol. XVI. 2 : 188-200.
Tinungki G.M. 2005. Evaluasi Model Produksi Surplus Dalam Menduga Hasil Tangkapan Maksimum Lestari Untuk Menunjang Kebijakan Pengelolaan Perikanan Lemuru di Selat Bali, Sekolah Pasca Sarjana, IPB.

Wudianto. 2001. Analisis Sebaran dan Kelimpahan Ikan Lemuru (Sardinella lemuru Bleeker 1853) di Perairan Selat Bali: Kaitannya dengan Optimasi Penangkapan, Program Pasca Sarjana, IPB. 